\title{
Application of queuing theory in inventory systems with substitution flexibility
}

\author{
S. M. Seyedhoseini • Reza Rashid • Iman Kamalpour • \\ Erfan Zangeneh
}

Received: 26 August 2014/ Accepted: 5 January 2015/Published online: 23 January 2015

(C) The Author(s) 2015. This article is published with open access at Springerlink.com

\begin{abstract}
Considering the competition in today's business environment, tactical planning of a supply chain becomes more complex than before. In many multi-product inventory systems, substitution flexibility can improve profits. This paper aims to prepare a comprehensive substitution inventory model, where an inventory system with two substitute products with ignorable lead time has been considered, and effects of simultaneous ordering have been examined. In this paper, demands of customers for both of the products have been regarded as stochastic parameters, and queuing theory has been used to construct a mathematical model. The model has been coded by $\mathrm{C}++$, and it has been analyzed due to a real example, where the results indicate efficiency of proposed model.
\end{abstract}

Keywords Inventory management - Substitution flexibility - Simultaneous ordering - Stochastic demand . Queuing theory

\section{Introduction}

One of the challenges in supply chain management is to find optimal policy for inventory system, the main objective of inventory management is to balance conflicting goals like optimization of stock costs and shortage costs (Arda and Hennet 2006). Using flexible inventories is one of the ways to reduce inventory costs. Flexibility could be

S. M. Seyedhoseini - R. Rashid · I. Kamalpour .

E. Zangeneh $(\square)$

Department of Industrial Engineering, Iran University of Science and Technology, Narmak, 16844 Tehran, Iran

e-mail: e.zangeneh@live.com considered in different ways, for example, through using product substitution, postponement (Tibben-Lembke and Bassok 2005) and lateral transshipments (Herer et al. 2006).

In substitution systems, flexible stock (mostly more expensive) will be used only when regular (cheaper) item stockout (Deflem and van Nieuwenhuyse 2011). For instance, if inventory of regular product cannot satisfy its demand, a higher quality item can be used as a substitute inventory (Liu and Lee 2007).

In summary, it is clear that despite many contributions in inventory management, there is little consideration due to substitution inventory models. In this paper, a stochastic stock control model has been proposed for two substitute products when lead time is ignorable, where the main contributions are summarized as follows.

- Demands have been considered as stochastic parameters.

- To prepare a comprehensive model, bi-level Markov process has been used.

- All the steady-state equations have been solved in terms of one state.

This model can be applied probably for inventory systems where demand is uncertain and two way substitutions can be used. For example, some items of dairy inventories have mostly stochastic demand, and some of them can use substitution with each other.

The reminder of this paper is organized as follows. In "Literature review", a brief literature review has been presented. In "Model development and analysis", first we represent a mathematical model for an inventory system with substitute products. The model is validated and some numerical examples are tested in "Solving approach". We conclude our study in "Numerical results". 


\section{Literature review}

There are lots of researchers that worked on inventory models. For instance, AriaNezhad et al. (2013) proposed a two echelon system for perishable items in supply chains, and used a case study to analyze their model.

Generally, in a supply chain, most of the parameters are not deterministic, for this reason, some researchers used queuing theory to construct a mathematical model. In this area, there are some who prepared a model for stochastic demand and some who prepared a model for stochastic lead time. Parlar (1996) presented an inventory model which was combined with queuing theory to consider demand and lead time stochastic parameters. Hosseini et al. (2013) considered stochastic lead time, and developed a multiobjective pricing-inventory model for a retailer, where their main objective was to maximize retailer's profit and service level. Seyedhoseini et al. (2014) considered poison demand for customers in a cross-docking problem, and prepare a stochastic model.

For better modeling of stochastic environment, some researchers used queuing theory, for example, Ha (1997) considered poison demand and exponential production times for a single-item make-to-stock production system. He proposed an $M / M / 1 / S$ queuing system for modeling the system. Arda and Hennet (2006) analyzed inventory control of a multi-supplier strategy in a two-level supply chain. They considered random arrival for customers and random delivery time for suppliers, and represented their system as a queuing network. Isotupa (2006), considered a lost sales $(s, Q)$ inventory system with two customer groups, and illustrated the model by Markov processes.

Babai et al. (2010) considered demand and lead time stochastic and analyzed a single-echelon single-item inventory system by means of queuing theory. Considering effectiveness of queuing theory in inventory problems, we also used queuing theory to develop our model. ToktasPalut and Ülengin (2011) coordinated the inventory policies in a two-stage decentralized supply chain, where each supplier has been considered as an $M / M / 1$ queue and the manufacture has been assumed as a $G / / M / 1$ queue.

Alimardani et al. (2013) applied continuous review ( $S-$ $1, S$ ) policy for inventory control and supposed a bi-product three-echelon supply chain which is modeled as an $(M / M /$ 1) queue model for each type of products offered through the developed network. In addition, to show the performance of the proposed bi-product supply chain, they also considered a network including two $(M / M / 1)$ queue for each type of products.

Some researchers studied substitution flexibility. For example, Bayindir et al. (2007) consider a one-way substitution system with two products which uses $S-1, S$ policy. They use a two-dimensional Markov process to develop the model, where the objective of their research was to find the optimal order up to levels. Liu and Lee (2007) proposed three different policies to use one-way substitution, and developed an inventory system with backlogs.

Olssen (2010) considered a continuous review inventory system where one-way lateral transshipment is allowed. Nagarajan and Rajagopalan (2008) dealt with a two-product problem, where substitution has been assumed for both of the products. Bahri and Tarokh (2012) presented a coordinated seller-buyer supply chain model in two stages, which is called Joint Economic Lot Sizing (JELS) in the literature. They assumed that the delivery lead time is stochastic and follows an exponential distribution and delivery activities consist of a single raw material. Tan and Karabati (2013) proposed an inventory management that incorporates the effects of stockout-based dynamic substitutions.

Deflem and van Nieuwenhuyse (2011) presented an approach to analyze two-item periodic inventory system with one-way substitution flexibility, where the objective function was to minimizing the expected purchasing costs, holding costs, shortage costs and adjustment costs. Ye (2014) dealt with the problem of inventory management and simultaneously horizontal (equivalently inter-brand) and vertical (equivalently intra-brand) substitution.

Considering great literature of stochastic inventory we prepare a table in which research on substitute flexibility and stochastic inventory have been analyzed.

As demonstrated in Table 1, there are some papers which dealt with the problem of $(R, Q)$ inventory in stochastic environment; however, only some of them considered substitution flexibility. Even among those researchers who worked on substitution flexibility, assumptions of two way of substitution and stochastic $(R$, $Q$ ) inventory are new.

\section{Model development and analysis}

In this paper, an inventory system with two substitute products has been considered where shortage is not allowed, and replacement causes costs for both of the products. For simplification of the system, it has been assumed that lead time is an ignorable value. In this research, demand of each product has been considered poison distributor, and Markov process has been used to model the system, where the states have been represented by $(I, J) . I$ and $J$ represent inventory levels for each type of products. For this queue, Fig. 1 demonstrates the transition diagram when both of the products are ordered together.

As it has been demonstrated in Fig. 1, states have been put into three sets, set $A$ and set $C$ represent the states which have only one type of inventories and the inventory level will be reduced if a demand for each kind of products 
Table 1 Classification of papers in stochastic inventory and substitution flexibility

\begin{tabular}{|c|c|c|c|c|c|c|c|}
\hline \multirow[t]{2}{*}{ Authors } & \multicolumn{2}{|l|}{ Shortage } & \multirow[t]{2}{*}{ Lead time } & \multirow[t]{2}{*}{ Demand } & \multirow[t]{2}{*}{ Replenishment policy } & \multicolumn{2}{|c|}{ Substitute flexibility } \\
\hline & Lost sales & Back order & & & & One way & Two way \\
\hline Parlar (1996) & & $\boldsymbol{v}$ & Stochastic & Stochastic & $(R, Q)$ & & \\
\hline Isotupa (2006) & & $\checkmark$ & Stochastic & Stochastic & $(R, Q)$ & & \\
\hline (Arda and Hennet 2006) & & $\checkmark$ & Stochastic & Stochastic & $(S-1, S)$ & & \\
\hline Boute et al. (2007) & & $\boldsymbol{V}$ & Stochastic & Stochastic & $(T, S)$ & & \\
\hline Olssen (2010) & $\checkmark$ & $\checkmark$ & Deterministic & Stochastic & $(R, Q),(S-1, S)$ & & \\
\hline Hill et al. (2007) & $\checkmark$ & & Deterministic & Stochastic & $(S-1, S)$ & & \\
\hline Hannet and Arda (2008) & & $\boldsymbol{V}$ & Stochastic & Stochastic & $(S-1, S)$ & & \\
\hline Teimoury et al. (2010) & & $\checkmark$ & Stochastic & Stochastic & $(R, Q)$ & & \\
\hline Toktas-Palut and Ülengin (2011) & & $\boldsymbol{v}$ & Stochastic & Stochastic & $(S-1, S)$ & & \\
\hline Babai et al. (2010) & & $\boldsymbol{V}$ & Stochastic & Stochastic & $(S-1, S)$ & & \\
\hline Tili et al. (2012) & $\checkmark$ & & Deterministic & Stochastic & $(T, s, S)$ & & \\
\hline Bahri and Tarokh (2012) & & $\boldsymbol{V}$ & Stochastic & Deterministic & $(R, Q)$ & & \\
\hline Alimardani et al. (2013) & & $\boldsymbol{V}$ & Stochastic & Stochastic & $(S-1, S)$ & & \\
\hline Guerrero et al. (2013) & No shortage & & Deterministic & Stochastic & $(T, s, S)$ & & \\
\hline Yu and Dong (2014) & No shortage & & Deterministic & Stochastic & $(R, Q)$ & & \\
\hline Baek and Moon (2014) & & $\checkmark$ & Stochastic & Stochastic & $(R, Q)$ & & \\
\hline Deflem and van Nieuwenhuyse (2011) & Combination & of both models & Deterministic & Stochastic & $(T, S)$ & $\checkmark$ & \\
\hline Ye (2014) & $\checkmark$ & & Deterministic & Stochastic & $(R, Q)$ & $\checkmark$ & \\
\hline Ahiska and kurtul (2014) & Combination & of both models & Deterministic & Stochastic & $(T, S)$ & $\checkmark$ & \\
\hline Salameh et al. (2014) & $\checkmark$ & & Deterministic & Deterministic & $(R, Q)$ & & $\boldsymbol{V}$ \\
\hline Krommyda et al. (2015) & $\boldsymbol{V}$ & & Deterministic & Deterministic & $(R, Q)$ & & $\boldsymbol{v}$ \\
\hline Our model & $\boldsymbol{\nu}$ & & Stochastic & Deterministic & $(R, Q)$ & & $\checkmark$ \\
\hline
\end{tabular}

Fig. 1 Transition diagram of proposed model

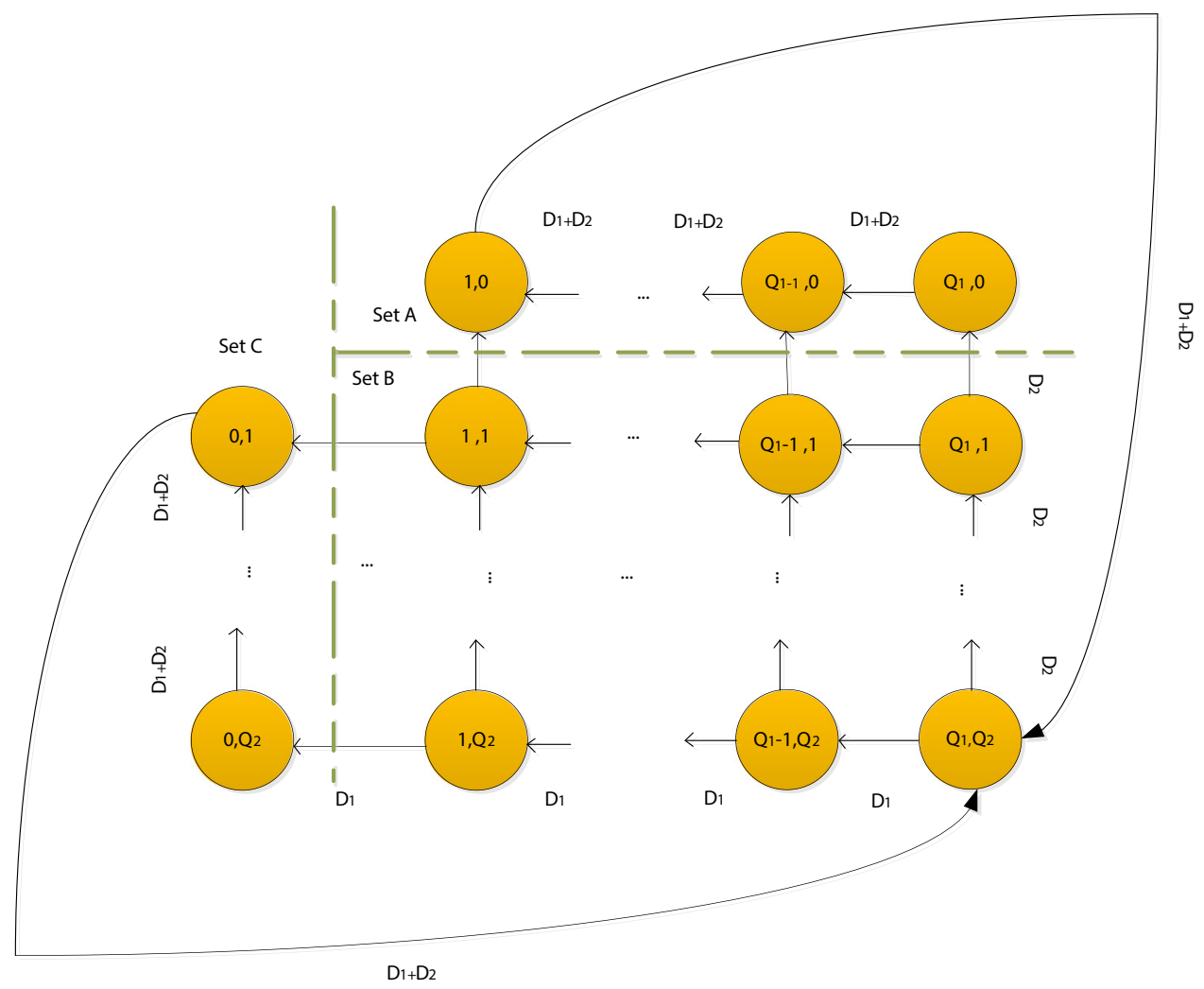




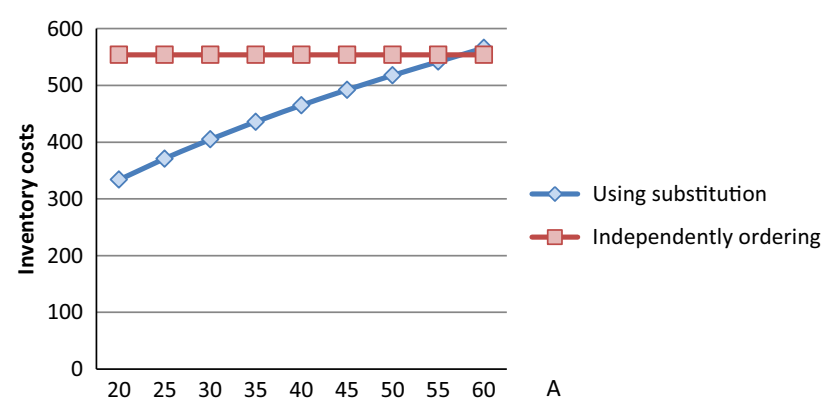

Fig. 2 Sensitivity of the models due to $A$

inters to the system. Set $B$ represents the states which have inventories for both kinds of products, and no substitution happens.

To prepare a comprehensive model, four lemmas have been proposed to calculate steady-state probabilities in terms of probability of state $\left(Q_{1}, Q_{2}\right)$. Henceforth, let $\pi_{i, j}$ denote steady-state probability of state $(I, J), D_{1}$ denote demand rate for type-one product, and $D_{2}$ denote demand rate for type-two product.

Lemma 1 In a network when flows arrive only through one state like set $B$, and flows only move to right or top, arrival flows to node $(I, J)$ would be sum of the flows which come from node $\left(Q_{1}, Q_{2}\right)$ through all the directions. If $\mathrm{IF}_{i, j}$ denotes interval flow for state $(I, J)$, and $\mathrm{IF}_{i, j}^{k}$ demonstrates arrival flow which comes through path $k$, and there are $N$ paths between state $\left(Q_{1}, Q_{2}\right)$ and $(I, J)$, so we have:

$\mathrm{IF}_{i, j}=\sum_{k=1}^{N} \mathrm{IF}_{i, j}^{k}$

Proof Arrival flow for this network only goes through node $\left(Q_{1}, Q_{2}\right)$. Consequently, each flow goes to state $(I, J)$ comes from state $\left(Q_{1}, Q_{2}\right)$. Considering flows only move to right or top, each path between node $\left(Q_{1}, Q_{2}\right)$ and node $(I, J)$, which has $I-1$ lateral movement and $J-l$ vertical movement consists a flow. Also flows only go through these paths, so $\mathrm{IF}_{i, j}$ is sum of flows that go through these paths and could be calculated by Eq. 1 .

Lemma 2 If Fig. 2, demonstrates a queuing network, where each node has vertical output rate with value of $D$ and lateral output rate with value of $\mu . \mathrm{IF}_{i, j}$ could be calculated by Eq. 2.

$\mathrm{IF}_{i, j}=\left(\left(\frac{D_{1}^{Q_{1}-i} D_{2}^{Q_{2}-j}}{\left(D_{1}+D_{2}\right)^{Q_{2}+Q_{1}-i-j}}\right)\left(\begin{array}{c}Q_{2}+Q_{1}-i-j \\ Q_{2}-j\end{array}\right)\right) \mathrm{IF}_{Q_{1}, Q_{2}}$

Proof $\mathrm{IF}_{k, m}$ has a vertical movement with probability of $\frac{D_{2}}{D_{1}+D_{2}}$ and a lateral movement with probability of $\frac{D_{1}}{D_{1}+D_{2}}$. Consequently if flow has a vertical movement, it will be multiplied by coefficient $\frac{D_{2}}{D_{1}+D_{2}}$, and if it has a lateral movement, it will be multiplied by coefficient $\frac{D_{1}}{D_{1}+D_{2}}$. Also between node $\left(Q_{1}, Q_{2}\right)$ and node $(I, J)$ there are $Q_{2}-j$ vertical movements and $Q_{1}-i$ lateral movements, consequently, in each path, input flow for $(I, J)$ is:

$\left(\frac{D^{i-1} \mu^{j-1}}{(\mu+D)^{j+i-2}}\right) \mathrm{IF}_{1,1}$

Also number of paths between node $\left(Q_{1}, Q_{2}\right)$ and node $(I, J)$ is:

$$
\left(\begin{array}{c}
Q_{2}+Q_{1}-i-j \\
Q_{2}-j
\end{array}\right)
$$

Considering lemma 1 and Eqs. 3 and 4, below expression can be obtained.

$$
\begin{aligned}
I F_{i, j}=\sum_{k=1}^{N} I F_{i, j}^{k}= & \left(\frac{D_{1}^{Q_{1}-i} D_{2}^{Q_{2}-j}}{\left(D_{1}+D_{2}\right)^{Q_{2}+Q_{1}-i-j}}\right) \\
I F_{Q_{1}, Q_{2}} \sum_{k=1}^{N} 1= & \left(\left(\frac{D_{1}^{Q_{1}-i} D_{2}^{Q_{2}-j}}{\left(D_{1}+D_{2}\right)^{Q_{2}+Q_{1}-i-j}}\right)\right. \\
& \left.\times\left(\begin{array}{c}
Q_{2}+Q_{1}-i-j \\
Q_{2}-j
\end{array}\right)\right) I F_{Q_{1}, Q_{2}}
\end{aligned}
$$

In this Markov process, output rate is equal to $D_{1}+D_{2}$, and below equation is true for steady-state probabilities.

$\left(D_{1}+D_{2}\right) \pi_{i, j}=\mathrm{IF}_{i, j}$

Consequently, $\mathrm{IF}_{Q_{1}, Q_{2}}$ is equal to $\frac{\mathrm{IF}_{Q_{1}, Q_{2}}}{D_{1}+D_{2}}$ and steady states for set $B$ can be calculated by Eq. 7 .

$\pi_{i, j}=\left(\left(\frac{D_{1}^{Q_{1}-i} D_{2}^{Q_{2}-j}}{\left(D_{1}+D_{2}\right)^{Q_{2}+Q_{1}-i-j}}\right)\left(\begin{array}{c}Q_{2}+Q_{1}-i-j \\ Q_{2}-j\end{array}\right)\right) \pi_{Q_{1}, Q_{2}}$

To calculate steady-state probabilities of set $A$, lemma 3 has been proposed.

Lemma 3 Steady-state probabilities for set $A$ can be calculated as follows

$$
\begin{aligned}
\pi_{i, 0}= & \sum_{s=0}^{Q_{1}-i} \pi_{Q_{1}-s, 1} \cdot \frac{D_{1}}{D_{1}+D_{2}}=\sum_{s=0}^{Q-i}\left(\begin{array}{c}
Q_{1}+Q_{2}-s-1 \\
Q_{2}-1
\end{array}\right) \\
& \cdot \pi_{Q_{1}, Q_{2}} \cdot \frac{D_{1}^{Q_{1}-s} \cdot D_{2}^{Q_{2}-1}}{\left(D_{1}+D_{2}\right)^{Q_{1}+Q_{2}-s-1}} \cdot \frac{D_{1}}{D_{1}+D_{2}}
\end{aligned}
$$

Proof All of the flows which arrive to set $A$ come from states which have $J=1$, and also states of set $A$ have only lateral rate with value of $D_{1}+D_{2}$. For state $(I, 0)$, Eq. 9 is true.

$\mu\left(\pi_{i, 0}\right)=D\left(\pi_{i, 1}+\pi_{i+1,1}+\cdots+\pi_{Q_{1}, 1}\right)$

Considering Eq. 9 and lemma 2, lemma 3 is proved.

Similar to set $A$, steady-state probabilities of set $C$ can be obtained as follows: 


$$
\begin{aligned}
\pi_{0, j}= & \sum_{s=0}^{Q_{2}-j} \pi_{0, Q_{2}-s} \cdot \frac{D_{2}}{D_{1}+D_{2}} \\
= & \sum_{s=0}^{Q-i}\left(\begin{array}{c}
Q_{1}+Q_{2}-s-1 \\
Q_{2}-s
\end{array}\right) \cdot \pi_{Q_{1}, Q_{2}} \\
& \cdot \frac{D_{1}^{Q_{1}-1} \cdot D_{2}^{Q_{2}-s}}{\left(D_{1}+D_{2}\right)^{Q_{1}+Q_{2}-s-1}} \cdot \frac{D_{2}}{D_{1}+D_{2}}
\end{aligned}
$$

Lemma 4 Amount of substitution for product 1 and product 2 is represented by Eqs. 10 and 11 .

$\sum_{j=1}^{Q_{2}} \pi_{1, j} \cdot j \cdot\left(\frac{D_{1}}{D_{1}+D_{2}}\right)^{2}$

$\sum_{i=1}^{Q_{1}} \pi_{i, 1} \cdot i \cdot\left(\frac{D_{2}}{D_{1}+D_{2}}\right)^{2}$

Proof State of $\pi_{1, j}$ changes to $\pi_{0, j}$ by probability of $\frac{D_{1}}{D_{1}+D_{2}}$, and then $\frac{D_{1} \cdot j}{D_{1}+D_{2}}$ substitution inventories must be used to satisfy demand of product 1 . Consequently, Eq. 11 calculates substitution amount for product 1 and similar to product 1, Eq. 12 calculates substitution amount for product 2 .

This section presents a mathematical model to solve the problem described above.

\section{Parameters}

$h_{1} \quad$ Holding costs for product 1

$h_{2} \quad$ Holding costs for product 1

$A_{1} \quad$ Ordering cost for product 1 for independently ordering

$A_{2} \quad$ Ordering costs for product 2 for independently ordering

A Ordering costs of simultaneous ordering

$D_{1}^{\prime} \quad$ Average demand for inventory of type one in a specific decision period

$D_{2}^{\prime} \quad$ Average demand for inventory of type two in a specific decision period

$c_{1} \quad$ Replacement costs for product 1

$c_{2}$ Replacement costs for product 2

\section{Variables}

$\pi_{\mathrm{i}, \mathrm{j}} \quad$ Steady-state probability of state $(I, J)$

$Q_{1} \quad$ Quantity of ordering for product one

$Q_{2} \quad$ Quantity of ordering for product two

Objective:

$$
\begin{aligned}
Z= & \sum_{j=0}^{Q_{2}} \sum_{i=0}^{Q_{1}}\left(h_{1} \cdot i\right) \cdot \pi_{i, j}+\sum_{j=0}^{Q_{2}} \sum_{i=0}^{Q_{1}}\left(h_{2} \cdot j\right) \cdot \pi_{i, j}+A \\
& \cdot\left(\frac{D_{1}^{\prime}+D_{2}^{\prime}}{Q_{1}+Q_{2}}\right)+c_{1} \cdot \sum_{j=1}^{Q_{2}} \pi_{1, j} \cdot j \cdot\left(\frac{D_{1}}{D_{1}+D_{2}}\right)^{2}
\end{aligned}
$$

Table 2 Example

\begin{tabular}{lllllllllll}
\hline$c_{2}$ & $c_{1}$ & $D_{2}$ & $D_{1}$ & $D_{2}^{\prime}$ & $D_{1}^{\prime}$ & $A$ & $A_{2}$ & $A_{1}$ & $h_{2}$ & $h_{1}$ \\
\hline 20 & 20 & 10 & 5 & 200 & 100 & 30 & 30 & 30 & 8 & 10 \\
\hline
\end{tabular}

Table 3 Comparison between using substitution and independently ordering

\begin{tabular}{lllllc}
\hline & \multicolumn{2}{c}{ Using substitution } & & \multicolumn{2}{c}{ Independently ordering } \\
\cline { 2 - 3 } \cline { 5 - 6 } \cline { 5 - 6 } & Product 1 & Product 2 & & Product 1 & Product 2 \\
\hline Ordering quantity & 10 & 37 & & 24 & 38 \\
$\begin{array}{l}\text { Costs of inventory } \\
\text { system }\end{array}$ & 405 & & 554 \\
\begin{tabular}{l} 
Substitution costs \\
\hline
\end{tabular} & 33 & & 0 \\
\hline
\end{tabular}

The objective function is composed of five sections. The first two sections are for calculating holding costs, third section calculates ordering costs. Forth section and fifth sections are to calculate substitution costs.

In this system, when each product is ordered independently, substitution will not used, and optimal ordering quantity for product 1 and 2 can be calculated by $\sqrt{\frac{2 \cdot A_{1} \cdot\left(D_{1}^{\prime}\right)}{h_{1}}}$ and $\sqrt{\frac{2 \cdot A_{2} \cdot\left(D_{2}^{\prime}\right)}{h_{2}}}$.

\section{Solving approach}

When there are two types of products with substitution flexibility, and $Q_{1}$ and $Q_{2}$ represent ordering quantity of these products, then if $Q_{2}$ becomes zero, optimal $Q_{1}$ will be the biggest amount that it can be. If only product 1 be ordered $\mathrm{CO}_{1}$ represents costs of the system and if only product 2 be ordered $\mathrm{CO}_{2}$ represents costs of the system.

$$
\begin{aligned}
& \mathrm{CO}_{1}=A \cdot\left(\frac{D_{1}^{\prime}+D_{2}^{\prime}}{Q_{1}}\right)+h_{1} \cdot \bar{I}_{1}+D_{2}^{\prime} \cdot c_{2} \\
& \mathrm{CO}_{2}=A \cdot\left(\frac{D_{1}^{\prime}+D_{2}^{\prime}}{Q_{1}}\right)+h_{2} \cdot \bar{I}_{2}+D_{1}^{\prime} \cdot c_{1}
\end{aligned}
$$

where $\bar{I}_{1}$ and $\bar{I}_{2}$ are equal to $\frac{Q_{1}}{2}$ and $\frac{Q_{2}}{2}$. And optimal $Q_{1}$ and $Q_{2}$ for $\mathrm{CO}_{1}$ and $\mathrm{CO}_{2}$ are $\sqrt{\frac{2 \cdot A \cdot\left(D_{1}^{\prime}+D_{2}^{\prime}\right)}{h_{1}}}$ and $\sqrt{\frac{2 \cdot A \cdot\left(D_{1}^{\prime}+D_{2}^{\prime}\right)}{h_{2}}}$. Consequently, Eqs. 16 and 17 can be used to limit feasible space of the problem.

$$
\begin{aligned}
& Q_{1} \leq \sqrt{\frac{2 \cdot A \cdot\left(D_{1}^{\prime}+D_{2}^{\prime}\right)}{h_{1}}} \\
& Q_{2} \leq \sqrt{\frac{2 \cdot A \cdot\left(D_{1}^{\prime}+D_{2}^{\prime}\right)}{h_{2}}}
\end{aligned}
$$




\section{Numerical results}

In this section, proposed model has been coded by $\mathrm{C}++$ software and an example has been produced in Table 2.

For this example, Table 3 compares using substitution with independently ordering, where superiority of substitution has been demonstrated.

Decision for this system, can be influenced by different parameters. For that matter, this section has analyzed the model due to different parameters. For the previous example, Fig. 2 illustrates sensitivity of the model due to $A$. Decision of using substitution or not depends on value of

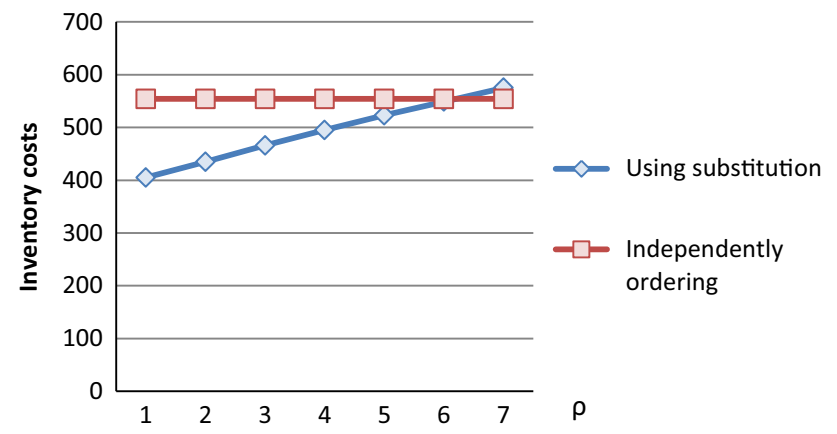

Fig. 3 Sensitivity of the models due to substitution costs

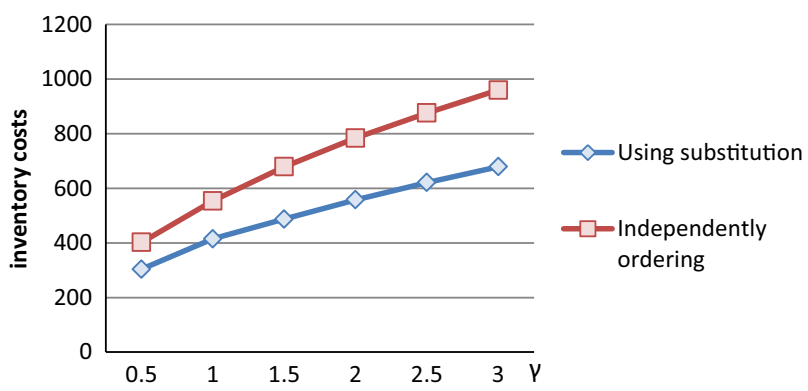

Fig. 4 Sensitivity of the models due to holding costs
$A$. For this example, if $A$ be less than 57 it would be affordable to use substitution, otherwise it can cause more costs than independently ordering. Consequently, it can be inferred that decision of independently ordering or simultaneous ordering (using substitution) are dependent on parameter of $A$.

To analyze sensitivity of substitution costs, it has been assumed that $\rho$ be a coefficient for both of products substitution costs and systems costs have been analyzed in Fig. 3 . Substitution costs effect decision of using substitution flexibility. In this example, if substitution costs be bigger than 120 , it is not affordable to use substitution flexibility.

To analyze sensitivity of holding costs, it has been assumed that $\gamma$ be a coefficient for both of products holding costs and systems costs have been analyzed in Fig. 4, where sensitivity of independent ordering due to holding costs is more than when substitution flexibility is used.

\section{Real example}

The proposed model can be appropriately used for Dairy supply chains. KALE Company produces Dairy products, and this company has two factories located in Amol and Karaj cities, and also 25 cities consisting majority of KALE customers.

In this supply chain, 25 retailers exist, where 18 retailers are for KALE and the other 7 retailers are acting in a decentralized supply chain. For most of these retailers, transportation is more than $3 \mathrm{~h}$ and there are only five retailers near KALE factories, which have less transportation time than $3 \mathrm{~h}$. For this reason, we only considered one retailer which has less transportation time than the other retailers. Ahamd Abad retailer is located at Tehran city and it acts in a centralized supply chain with KALE.

KALE has some characteristics that make it suitable for our model. First its production rate is high, and it has a

Table 4 Comparison between using substitution and independently ordering for cream cheese and Amol cheese

\begin{tabular}{|c|c|c|c|c|c|c|}
\hline & \multicolumn{2}{|c|}{ Using substitution } & \multicolumn{2}{|c|}{ Independently ordering } & \multicolumn{2}{|c|}{ Current policy in company } \\
\hline & Product 1 & Product 2 & Product 1 & Product 2 & Product 1 & Product 2 \\
\hline Ordering quantity & 1,520 & 3,640 & 3,330 & 3,560 & 2,100 & 21,000 \\
\hline Costs of inventory system & 1,513 & & 2,633 & & 2,124 & \\
\hline
\end{tabular}

Table 5 Comparison between using substitution and independently ordering for low-fat Tetra milk and low-fat Manshori milk

\begin{tabular}{|c|c|c|c|c|c|c|}
\hline & \multicolumn{2}{|c|}{ Using substitution } & \multicolumn{2}{|c|}{ Independently ordering } & \multicolumn{2}{|c|}{ Current policy in company } \\
\hline & Product 1 & Product 2 & Product 1 & Product 2 & Product 1 & Product 2 \\
\hline Ordering quantity & 1,330 & 2,640 & 2,630 & 2,780 & 1,850 & 1,850 \\
\hline Costs of inventory system & 1,851 & & 3,210 & & 2,520 & \\
\hline
\end{tabular}


Table 6 Comparison between using substitution or independently ordering IML yogurt and Ps yogurt

\begin{tabular}{|c|c|c|c|c|c|c|}
\hline & \multicolumn{2}{|c|}{ Using substitution } & \multicolumn{2}{|c|}{ Independently ordering } & \multicolumn{2}{|c|}{ Current policy in company } \\
\hline & Product 1 & Product 2 & Product 1 & Product 2 & Product 1 & Product 2 \\
\hline Ordering quantity & 2,160 & 1,210 & 2,300 & 2,120 & 1,450 & 1,450 \\
\hline Costs of inventory system & 1,100 & & 1,950 & & 1,760 & \\
\hline
\end{tabular}

small transportation time for Ahmad Abad retailer, so we could consider lead time as an ignorable parameter. On the other hand, demand of Ahmad Abad is high. For this reason, we considered poison distribution for demand of each retailer.

Although KALE Company produces different kinds of Dairy products, we only considered three kinds of products that can use substitution. For this company, cream cheese and Amol cheese, low-fat Tetra milk and low-fat Manshori milk, and IML yogurt and Ps yogurt are substitute products. This company has same ordering quantity for each of these kinds of products. For this case, analyses of these three substitution products have been represented in Tables 4, 5 and 6 , where costs are in 1,000,000 Rials.

As demonstrated in these tables, current policy is to order in same quantity for each kind of substitute products. Using this policy, their costs are lesser than when they use independent ordering. But using substitution flexibility they can improve inventory costs significantly, where major reason is decrease in ordering costs. Using substitution, overall ordering quantity has been increased, where 1794 items have been increased for cheese, 270 items increased for milk, and 470 items for yogurt; however, $611,000,000$ Rials for cheese, 669,000,000 Rials for milk and 660,000,000 Rials for yogurt would diminish.

\section{Conclusion}

In this research, an inventory system with two substitute products with ignorable lead time and stochastic demand has been considered, and by means of queuing theory a mathematical model has been proposed. For this system, steady-state equations have been solved and all of the steady-state probabilities have been calculated in terms of $\pi_{Q_{1}, Q_{2}}$.

In this paper, the model has been analyzed due to different parameters and their behaviors have been discovered. Using substitution requires simultaneous ordering and it can be compared with the situation when different items use independent ordering. It is clear that, sometimes decision of using substitution and simultaneous ordering is not affordable and it depends on values of problem parameters, so we analyzed this too.
We also prepared a real example, which is for Kale Company. Inventory costs of this Company for three kinds of substitution products have been analyzed, and effectiveness of the model has been revealed.

For future studies, this research can be extended by considering substitution stock control system for more than two products with different substitution relations, this may increase complexity of the problem but the model would become more realistic. Another extension of this research is possible by considering rate of corruption for perishable inventories.

Open Access This article is distributed under the terms of the Creative Commons Attribution License which permits any use, distribution, and reproduction in any medium, provided the original author(s) and the source are credited.

\section{References}

Ahiska SS, Kurtul E (2014) Modeling and analysis of a product substitution strategy for a stochastic manufacturing/remanufacturing system. Comput Ind Eng 72:1-11

Alimardani M, Jolai F, Rafiei H (2013) Bi-product inventory planning in a three-echelon supply chain with backordering, Poisson demand, and limited warehouse space. J Ind Eng Int 9:22

Arda Y, Hennet J (2006) Inventory control in a multi-supplier system. Int J Prod Econ 104:249-259

AriaNezhad MG, Makuie A, Khayatmoghadam S (2013) Developing and solving two-echelon inventory system for perishable items in a supply chain: case study (Mashhad Behrouz Company). J Ind Eng Int 9:39

Babai MZ, Jemai Z, Dallery Y (2010) Analysis of order-up-to-level inventory systems with compound Poisson demand. Eur J Oper Res $552-558$

Baek J, Moon SK (2014) The M/M/1 queue with a productioninventory system and lost sales. Appl Math Comput 233:534-544

Bahri M, Tarokh MJ (2012) A seller-buyer supply chain model with exponential distribution lead time. J Ind Eng Int 8-13

Bayindir ZP, Erkip N, Güllü R (2007) Assessing the benefits of remanufacturing option under one-way substitution. J Oper Res Soc 56:286-296

Boute RN, Disney SM, Lambercht MR, Houdt BV (2007) An integrated production and inventory model to dampen upstream demand variability in the supply chain. Eur $\mathbf{J}$ Oper Res 178(1):121-142

Deflem Y, van Nieuwenhuyse I (2011) Optimal pooling of inventories with substitution: a literature review. Rev Bus Econ 56(3):345-374

Guerrero W, Yeung T, Guéret C (2013) Joint-optimization of inventory policies on a multi-product multi-echelon 
pharmaceutical system with batching and ordering constraints. Eur J Oper Res 231(1):98-108

Ha AY (1997) Stock rationing policy for a make-to-stock production system with two priority classes and backordering. Nav Res Logist $457-472$

Hannet J, Arda Y (2008) Supply chain coordination: a game-theory approach. Eng Appl Artif Intell 21(3):399-405

Herer YT, Tzur T, Yücesan E (2006) The multilocation transshipment problem. IIE Trans 38:185-200

Hill RM, Seifbarghy M, Smith DK (2007) A two-echelon inventory model with lost sales. Eur J Oper Res 181(2):753-766

Hosseini Z, Yaghin RG, Esmaeili M (2013) A multiple objective approach for joint ordering and pricing planning problem with stochastic lead times. J Ind Eng Int 9:29

Isotupa KPS (2006) An (s, Q) Markovian inventory system with lost sales and two demand classes. Math Comput Model 687-694

Krommyda IP, Skouri K, Konstantaras I (2015) Optimal ordering quantities for substitutable products with stock-dependent demand. Appl Math Model 39(1):147-164

Liu J, Lee C (2007) Evaluation of inventory policies with unidirectional substitution. Eur J Oper Res 182:145-163

Nagarajan M, Rajagopalan S (2008) Inventory models for substitutable products: optimal policies and heuristics. Manag Sci 54(8):453-1466

Olssen F (2010) An inventory model with unidirectional lateral transshipments. Eur J Oper Res 200:725-732

Parlar M (1996) Continuous-review inventory problem with random supply interruptions. Eur J Oper Res 366-385

Salameh MK, Yassine AA, Maddah B, Ghaddar V (2014) Joint replenishment model with substitution. Appl Math Model 38(14):3662-3671
Seyedhoseini SM, Rashid R, Teimoury E (2014) Developing a crossdocking network design model under uncertain environment. J Ind Eng Int. doi:10.1007/s40092-014-0088-0

Tan B, Karabati S (2013) Retail inventory management with stock-out based dynamic demand substitution. Int J Prod Econ 145:78-87

Teimoury E, Modarres M, Ghasemzadeh F, Fathi M (2010) A queuing approach to production-inventory planning for supply chain with uncertain demands: case study of PAKSHOO chemicals company. J Manuf Syst 29(2):55-62

Tibben-Lembke RS, Bassok Y (2005) An inventory model for delayed customization: a hybrid approach. Eur J Oper Res 165:748-764

Tili M, Moalla M, Campagne J (2012) The trans-shipment problem in a two-echelon, multi-location inventory system with lost sales. Int J Prod Res 50(13):3547-3559

Toktas-Palut P, Ülengin F (2011) Coordination in a two-stage capacitated supply chain with multiple suppliers. Eur J Oper Res 43-53

Toktaş-Palut P, Ülengin F (2011) Coordination in a two-stage capacitated supply chain with multiple suppliers. Eur J Oper Res 212(1):43-53

Ye T (2014) Inventory management with simultaneously horizontal and vertical substitution. Int J Prod Econ 156:316-324

Yu A, Dong Y (2014) A numerical solution for a two-stage production and inventory system with random demand arrivals. Comput Oper Res 44:13-21 